\title{
A Measure for the Study of Friendship and Romantic Relationship Quality from Adolescence to Early-Adulthood
}

\author{
Lucia Ponti, Silvia Guarnieri, Andrea Smorti and Franca Tani*
}

Department of Psychology, University of Florence, Italy

\begin{abstract}
Friendship and romantic relationships are central to individual social life. These close relationships become increasingly significant during adolescence and early adulthood, promoting human development and well-being [1]. Despite their importance, there are no equivalent measures for the study of the quality of these different types of close relationships.

The main aim of the present study was to develop an equivalent self-report measure to assess the quality of friendships and romantic relationships from adolescence to early adulthood. In Study 1 we took the Friendship Qualities Scale (FQS) developed by Bukowski, Hoza and Boivin [2] and adapted it for Italian adolescents and early-adults. The FQS reveals, via confirmatory factor analysis, five main qualitative dimensions: Conflict, Companionship, Help, Security and Closeness. In Study 2 we developed an equivalent version of the FQS, the Romance Qualities Scale (RQS) in order to measure the same five dimensions for romantic relationships.

Data analyses verified the multidimensional factorial structure, the factorial invariance, and the reliability of both scales. Our studies therefore verify that the FQS and RQS are reliable measures to assess friendship and romantic relationship quality from adolescence to early adulthood.
\end{abstract}

Keywords: Friendship, romantic relationship, equivalent measure, adolescence, early-adulthood.

\section{INTRODUCTION}

Over the last few decades, extrafamiliar relationships have been a topic of great interest in developmental psychology. Indeed, friendships and romantic relationships provide a significant context for development and psychosocial adaptation to take place within $[1,3-6]$. These close relationships become increasingly significant in people's lives as they move from childhood to adolescence and early adulthood promoting social and emotional development and contributing to overall well-being [7-14].

Despite the existing body of literature on the importance of these close relationships, there is a paucity of standardized, reliable measures which assess friendships and romantic relationships using a common conceptual framework. This indeed may be one of the reasons why the empirical research studies to date on these different close relationships have remained relatively conceptually disconnected from one another.

The development of multidimensional, equivalent instruments to assess friendships and romantic relationships would therefore assist in the systematic testing and comparison of differences and similarities between these different

*Address correspondence to this author at the Department of Psychology, University of Florence, Via San Salvi, 12, Pad. 26 - 50135, Florence, Italy; Fax: 0039-055-6236047; Tel: 0039-055-6237812;

E-mail: franca.tani@psico.unifi.it types of close relationships during adolescence and early adulthood. With regard to this, employment of self-report measures allows for the revelation of the fundamental aspects of the subjective experience via an inexpensive and easy administration procedure that ensures the respondent's privacy. Individuals' perceptions provide unique and reliable information about their impressions and evaluations of, as well as their expectations given, the history of their relationships. Respondents' perceptions of their friends and romantic partners significantly influence their attitude and behavior in relation to their social partners and consequently the quality of their interactions $[15,16]$. Moreover, as some research has suggested, subjective evaluations of relationships may have a stronger impact on individual adjustment than do objective indices $[15,17]$. Finally, respondents' ratings offer a common metric which enables comparison of different types of relationships.

With these considerations in mind, the present study aimed to develop an equivalent self-report measure for the study of the fundamental qualitative aspects of friendships and romantic relationships. Specifically, Study 1 aimed to take a reliable friendship quality self-report measure for nonItalian pre-adolescents and to adapt it to the Italian population for early adolescents through to early adults. Study 2 instead sought to develop an equivalent version of this measure for romantic relationships, which would be valid for adolescence and early adulthood. 


\section{STUDY ONE}

\section{Introduction}

A broad body of studies has demonstrated that friendships are central to individual social life across the lifespan $[18,19]$. These relationships significantly promote autonomy, self-esteem, identity [20, 21], and social-cognitive development [22-24]. Friendships also influence overall adjustment and individual well-being [25, 26].

With the advent of adolescence, aggregation experiences and friendships become fundamentally important. During adolescence and early adulthood, interactions with peers take on an increasingly higher priority, and develop into a forum for questioning and resolving personal identity issues [6]. More time is spent with peers, whose opinions come to play a critical role in individuals' thinking and decision-making. Close friends are perceived as the primary sources of guidance, opinion formation and social support. Furthermore, intimacy, mutuality, and self-disclosure with friends peak during this developmental stage [27]. Peers may also provide a refuge from conflict within family relations and be a resource in the adolescent's and early adult's bids for greater independence. Conformity to the peer group in terms of values, behavior, and preferences increases. The peer group becomes a normative point of reference, a privileged setting within which each individual can mature and experience new social roles and self emerging aspects [28-30], as well as within which he or she can learn more efficient strategies for conflict and its resolution [21, 24, 31, 32].

Given the growing importance of friendships in determining individual social development and adjustment, researchers have long studied its emotional and psychological characteristics (reciprocal support, intimacy, trust, conflict, aid, and so on). These studies have shown the multidimensional nature of friendships, characterized by positive aspects, which seem to reflect warmth, support or positive exchanges, as well as negative characteristics, such as conflict and competition [15]. From a methodological point of view, their multidimensional nature has lead to the development of comprehensive and multifactorial measures of friendship.

A critical evaluation of existing friendship measures in the literature was conducted and following this we decided to take the Friendship Qualities Scale (FQS) developed by Bukowski, Hoza and Boivin [2] and to adapt it for the Italian context. One of the qualities of this scale is that, in comparison to similar instruments, FQS assesses subjects' actual perceptions of friendships relations and not their abstract concepts of it. In other words, the scale's items refer to concrete behaviors that are situated in "real" situations with a "real" friend. Furthermore, this scale reveals the principal qualitative dimensions that characterize friendships during childhood and early-adolescence. Lastly, FQS has a complex conceptual structure and good psychometric characteristics, agility and easy administration procedure, which make it a particularly useful and valuable measure for psychological research.

\section{The Friendship Qualities Scale (FQS)}

The Friendship Qualities Scale (FQS) is a multidimensional self-report scale that measures early-adolescents' perceptions of the main qualitative characteristics that represent their bond with their best friend. The FQS was largely based on the interview developed by Berndt and Perry [33] which sought to measure friendship quality. Using this interview protocol as a starting point, Bukowski and colleagues [2] developed a paper-and-pencil format version of the interview, which consisted of 30 items that assessed six dimensions: play/association, pro-sociability, intimacy, loyalty, conflict, and self-esteem/attachment. Based on empirical and conceptual considerations, Bukowski et al. [2] revised their preliminary original version and developed a self-report scale consisting of 23 items which assessed five fundamental dimensions that connote the quality of friendship.

The five dimensions are: 1) Companionship, which refers to the amount of time that people voluntarily spend together; 2) Conflict, which refers to the frequency of disagreements in the friendship; 3) Help, which consists of two subcomponents, firstly assistance and mutual aid, and secondly protection in the face of injustice and oppression of others; 4) Security, which includes two key components of friendships: reliability, that is confidence that a friend can be trusted and the ability to overcome problems, namely the belief that friendship is a strong bond which can continue despite problems or conflict; 5) Closeness, which includes aspects relating to the strength of the emotional connection and attachment to a friend, along with the sense of affection or "specialness" that a person experiences with the friend.

Prior to filling out the questionnaire, respondents were asked to choose the friend whom they considered to be most important or closest to them and to answer the questions on the scale with their real relationship with this person in mind. Response choices for each item were rated on a 5point Likert scale from 1 (Absolutely false) to 5 (Absolutely true). Subscale scores were derived by calculating the arithmetic sum of values assigned by respondents to each item, keeping in mind that, as is the case in the original version, the score for item 13 must be encoded in reverse.

From a psychometric point of view, the FQS has shown a solid factorial structure and has good reliability indices. Indeed, this model has appeared to fit data reasonably well and the internal consistency of each of the five subscales has been shown to range from .71 and .86 [2].

Subsequently, Fonzi, Tani, and Schneider [34] developed an Italian adaptation of the scale, which they validated on a sample of younger children, aged 8 to 9 years. Exploratory and confirmatory factor analyses confirmed the original structure of the scale in the Italian context, with the exception of an item of the Companionship dimension ("My friend and I go to each other's houses after school and on weekends"), for which saturation was not significant. Therefore this item was dropped and the Italian version consisted of 22 items. Further, the Italian version discriminated amongst youngsters whose friendships were stable from youngsters whose friendships had terminated, providing evidence of concurrent validity. Finally, the internal consistencies of the five dimensions were adequate, ranging from .66 to .82 . 


\section{Aims of the Study}

With these considerations in mind, the principal aim of this study was to test if the Italian version of the Friendship Qualities Scale [34] which has already been developed for children, also holds for older subjects in order to have the same instrument that permits assessment of the qualitative dimensions of friendship across a broad age range. More specifically, the purpose of this first study is to: 1) evaluate the factor structure of the FQS on a sample of earlyadolescents via confirmatory factor analysis; 2 ) test factorial invariance across independent samples extracts from different populations (early-adolescents, middle-adolescents, and early-adults); and 3) investigate the reliability of the scale.

\section{METHOD}

\section{Subjects}

A total of 698 students were recruited for the present study and divided into three age groups:

1) 232 early-adolescents (108 males and 124 females) aged 12 to $14(M=13.08 ; S D=.79)$ who were attending secondary school and who were randomly selected from all the secondary schools in the metropolitan area of Florence.

2) 233 middle-adolescents (109 males and 124 females) aged 16 to $18(M=17.12 ; S D=.71)$ who were attending three high schools in Florence (a Lyceum specializing in classical studies, a Technical Institute, and a Vocational institute) and who were selected according to a random criterion.

3) 233 early-adults (101 males and 132 females) aged 20 to $23(M=21.77 ; S D=.80)$ who were studying at two departments of the university of Florence (the Psychology Faculty and the Law Faculty).

Participants were from Italian backgrounds and came from families who had middle to high socioeconomic status. Approximately $70 \%$ of their parents had a high school diploma or university degree $(42.9 \%$ of fathers had a high school diploma and $25 \%$ had a university degree; and $44.5 \%$ of mothers had a high school diploma and $23.9 \%$ of them had a university degree). Moreover, $96.7 \%$ of fathers were employed and only $3.3 \%$ of them were not employed. Finally, $80.4 \%$ of mothers were employed and $19.6 \%$ of them were not employed.

\section{Procedure}

The Italian version of the FQS which was developed for use with children by Fonzi et al. [34] had already been adapted and some items had been changed in order to make it appropriate to measure the behavioral patterns that are typical of older subjects. For example, we transformed the original item 12 "If I forgot my lunch or needed a little money, my friend would loan it to me" to "If I needed money, my friend would loan it to me". We therefore deleted an aspect that is more specific to younger subjects such as sharing lunch with a friend. Moreover, we modified the original item 9, "I can get into fights with my friends", to "Sometimes I quarrel, even violently, with my friend". Specifically, we reasoned that a fight is a behavior that is more typical of younger age group.
After subjects agreed to participate in the present study, they were asked to anonymously complete the Italian version of the FQS [34] in the classroom during normal school hours. For the first two groups, formal consent from parents and educational authorities was obtained prior to commencing with data collection. Participants were asked to respond to the questionnaire with sole reference to the relationship that they have with their current best friend.

\section{RESULTS}

\section{Preliminary Analyses}

Before analyzing the data we conducted a preliminary analysis designed to test the normality of all the items comprising the scale [35]. This was done separately for the three age groups. Analyses revealed a non-normal distribution for three items (items 6, 14, and 15) in relation to each of the three age groups. These items were normalized using standard transformations (logarithmic and square root) which brought the value of asymmetry to within the range of +1 and $-1[36,37]$.

\section{The Confirmative Factor Analysis}

The factorial structure of the scale was tested on the sample of early-adolescents via confirmatory factor analysis [38]. The analysis was performed using the AMOS 5.0 statistical program [39].

The adequacy of the model was evaluated by $\chi^{2}$ test. However, since this index is strongly influenced by sample size and is therefore an ambiguous index of the goodness of fit of the model [40-42], we considered other indices. As such goodness of fit was evaluated using Bentler's [43] Comparative Fit Index (CFI), Tucker and Lewis's [44] Tucker and Lewis Index (TLI), the Root Mean Square Error of Approximation (RMSEA) [45] and its 90\% confidence interval (90\% CI), and Bentler's [46] Standardized Root Mean Square Residual (SRMR). Multiple indices were selected as they provide different information for evaluating the fit of the model (for example, absolute fit, or fit relative to a null model). Used together, these indices provide a more reliable evaluation of the model's fit [47].

There were 22 observed variables and 5 latent variables in the model which was tested (Fig. 1).

Though chi-square was significant, due to the large sample size, all of the subjective fit indices satisfied the criteria suggesting that there was an acceptable model-data fit, and confirming the adequacy of the tested structure: $\chi^{2}=339.72$, $\mathrm{p}<.001, \chi^{2} / \mathrm{df}=1.89, \mathrm{CFI}=.91, \mathrm{TLI}=.90, \mathrm{RMSEA}=.06$ $(90 \%$ CI: $.05, .07)$, SRMS $=.07$.

Furthermore, the analysis carried out on the modified model presented significant saturations for all 22 items of the questionnaire.

Finally, the correlations among the five factors indicate a significant and positive relationship between the Companionship, Help, Security, and Closeness dimensions and a significant, negative relationship between these dimensions and the Conflict dimension (Fig. 2). 


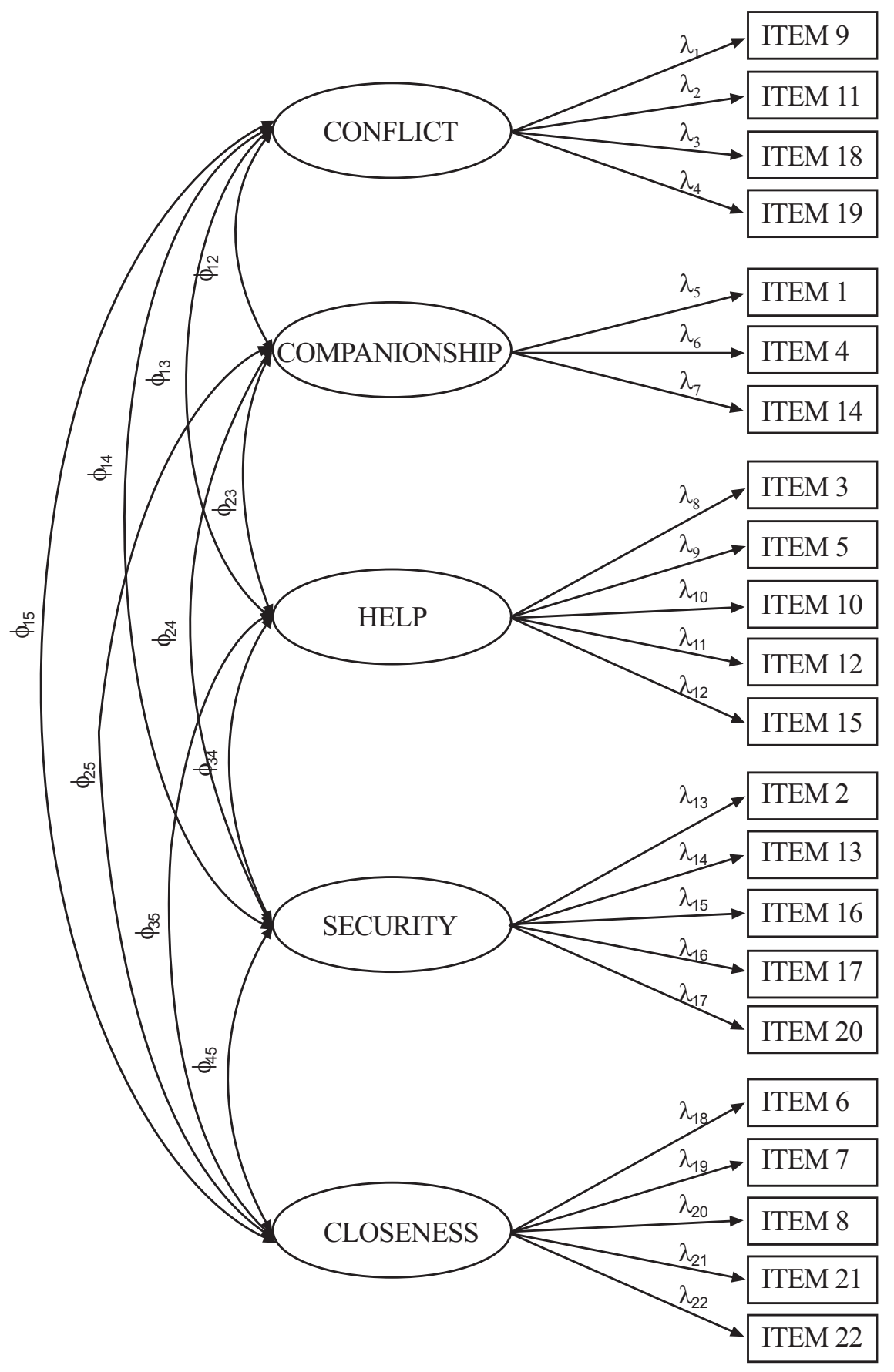

Fig. (1). Factorial structure of the FQS and RQS.

\section{Factorial Invariance}

Subsequently, in order to test the generalizability of the multidimensional structure of the FQS, we proceeded to verify the factorial structure across independent samples extracted from different populations, using a multi-group model that examines the moderating effect of a categorical variable on the relationship between constructs [48]. To do this we used the early-adolescent group, upon which the confirmatory factor analysis was conducted, as a calibration sample and the middle-adolescent and early-adulthood groups as validation samples $[49,50]$.
The invariance analysis provides the use of an omnibus test to assess the equivalence of the variance-covariance structure across groups as well as an overall index of the model that is tested simultaneously in the samples. This analysis starts with verification of the Baseline model with respect to structural invariance, in which all parameters are left free to vary and, if this model is verified, we proceed step by step, maintaining the previous restriction and adding increasingly restrictive levels of equality, which define levels of invariance [51]. In particular, after having verified the fit of the FQS base model, we tested the saturation invariance 


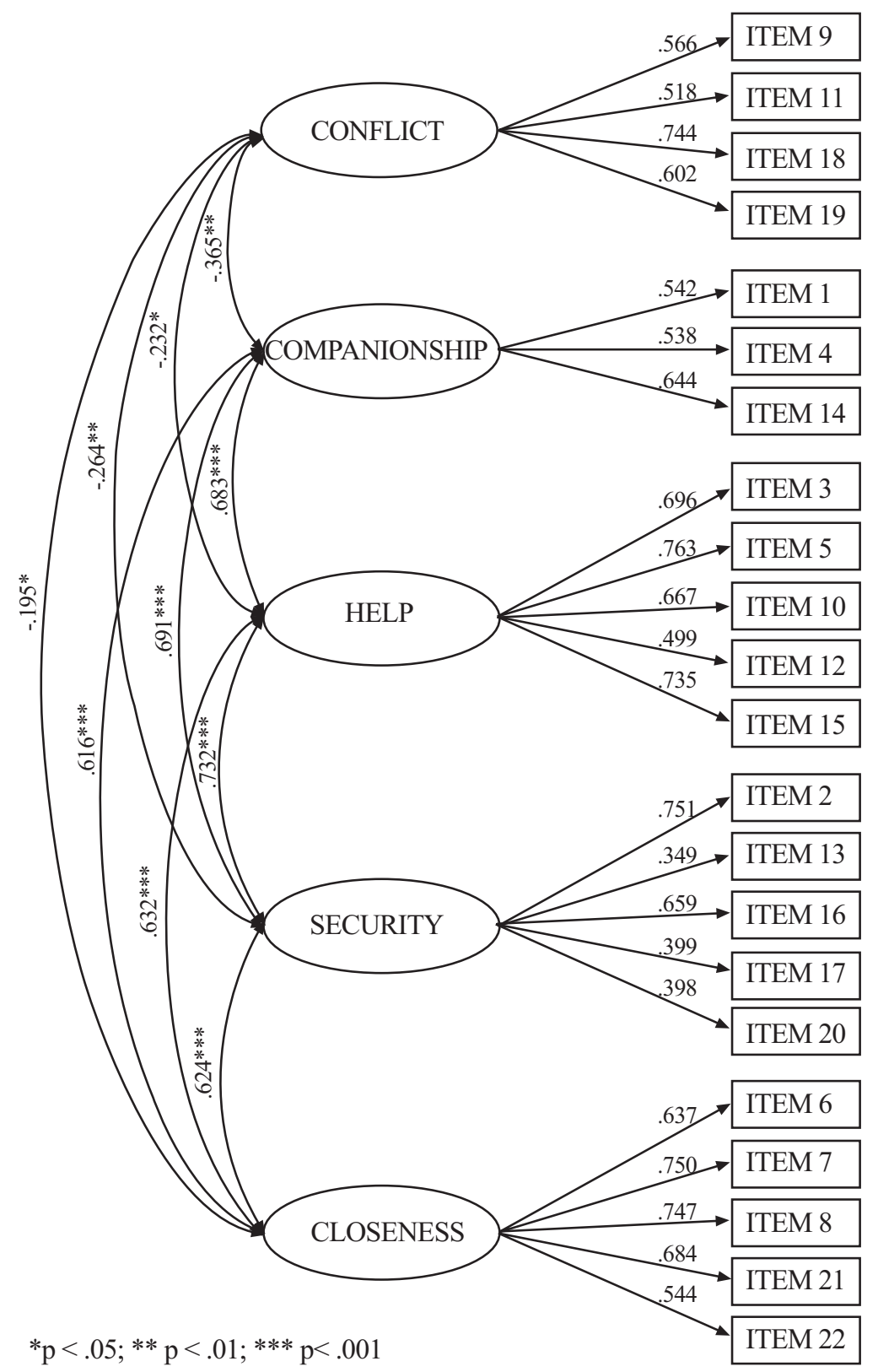

Fig. (2). Results of the confirmatory factor analysis conducted on the model of the FQS.

$(\lambda)$, factor covariance invariance $(\varphi)$ and, finally, the error term invariance $(\delta)$.

As shown in Table 1, the results of these analyses show the invariance of the factorial structure of the scale at all levels considered: the saturation invariance (Model 1), the factor covariance invariance (Model 2) and finally, the error term invariance (Model 3).

\section{Internal Consistency}

The internal consistency among the items of each dimension was assessed using Cronbach's coefficient alpha which was calculated separately for the three subject groups. The alpha range was .70 to .71 for the Conflict dimension, .62 to .64 for the Companionship dimension, .75 to .82 for the Help dimension, .67 to .70 for the Security dimension, and .78 to .79 for the Closeness dimension.

\section{DISCUSSION}

On the whole, the Italian version of the FQS for adolescents showed satisfactory psychometric properties and good generalizability and reliability.

Our results replicate the structure on the five dimensions suggested by the authors of the instrument [2] which were also later confirmed for children by Fonzi and colleagues [34].

A very interesting aspect of our results is the fact that the structure did not vary with respect to the three age groups considered. This result confirms that the proposed model can be generalized to different populations and that the use of the scale can be extended to subjects who are older than those for which the instrument was originally developed. 
Table 1. Index of the Factorial Invariance of the FQS: Saturation Invariance (Model 1), Factor Covariance Invariance (Model 2), and Error Term Invariance (Model 3)

\begin{tabular}{|c|c|c|c|c|c|c|c|}
\hline & $\chi^{2}$ & gdl & $\Delta \chi^{2}$ & $\Delta$ gdl & $\mathbf{p}\left(\Delta \chi^{2}\right)$ & CFI & RMSEA \\
\hline Baseline & 1013.93 & 531 & - & - & - & .91 & $.0490 \%$ C.I.: .04; .04 \\
\hline Model 1 & 1043.89 & 563 & 29.96 & 32 & ns & .91 & $.0390 \%$ C.I.: $.03 ; .04$ \\
\hline Model 2 & 1064.43 & 593 & 50.50 & 62 & $\mathrm{~ns}$ & .91 & $.0390 \%$ C.I.: .03; .04 \\
\hline Model 3 & 1104.99 & 639 & 91.07 & 108 & $\mathrm{~ns}$ & .91 & $.0390 \%$ C.I.: .03; .04 \\
\hline
\end{tabular}

Finally, our data showed that the FQS has adequate internal consistency [52], which confirms the results obtained by other authors $[2,34]$.

\section{STUDY 2}

\section{Introduction}

Although, as noted, close friends represent a fundamental part of an adolescent's social network, the exploration of romantic relationships is a new exciting challenge that begins in adolescence [6]. During early adolescence in particular, romantic relationships are casual, less intense, and shortlived [53]. During middle adolescence onwards, interest and interaction with opposite sex partners increase [54], and during late adolescence, the importance of romantic partners as providers of social support and intimacy gradually grows $[16,55-57]$. During the latter stages of adolescence and the first years of adulthood, romantic partners have stronger feelings of affection and deeper intimacy and commitment, manifest greater levels of care and comfort, and usually engage in more frequently sexual activity. Therefore, with age, romantic partners achieve a higher position within the adolescent's social network in terms of meeting and satisfying needs for support, intimacy, and closeness.

Studies have also shown links between romantic relationships and adolescents and early adults adaptation. It has been found that romantic involvement influences social competence [58], self-esteem [59], and identity and other components of self-concept development [60]. Further, within romantic relationships, individuals may also learn relational patterns that influence the course of subsequent relationships [61]. In addition, it was found that a negative quality of individuals' romantic relationship could predict depressive symptoms [11], and internalizing and externalizing disorders [62]. Romantic relationship quality therefore affects current functioning and later psychosocial development [14].

The fundamental role of romantic relationships in promoting individual adjustment and well-being is linked to their psychological functions and their emotional and psychological characteristics. Specifically, studies have shown that friendship and romantic relationships are characterized by a multidimensional nature that implies the presence of similar both positive (intimacy, support, aid, appreciation and admiration, specialness, nurturance and affection, togetherness or reliable alliance, exhilaration and companionship) and negative aspects (painfulness, conflict and negative interactions) [63, 64].
It is therefore evident how in many ways the majority of the dimensions that characterized the romantic relationships are similar to those of friendships. This is no surprise because, as many studies have shown, friendships and romantic relationships are very strongly connected, above all during adolescence $[55,65,66]$. In fact, peer relationships and close reciprocal friendship during this phase contribute to the behavioral and emotional patterns that characterize romantic relationships [67]. In particular, "youngsters who have experienced genuine intimacy in the context of a close friendship move into the adolescent period with an experiential basis for establishing closeness and intimacy with a romantic partner" (p. 270) [68].

Beyond these overlapping dimensions, which friendship and romantic relationships have in common, romantic relationships nevertheless present some characteristics that are typical and specific to these types of intimate relationships, like passion and sexuality that are of great relevance in defining the quality of the romantic relationship. Despite this, since the aim of our study is to adapt an equivalent instrument that permits comparison of the typical and specific qualitative characteristics of romantic and friendship relationships, the dimensions related to love and sexuality were not taken into consideration.

It is worth noting that interest in the scientific study of adolescent and early adult romance has only begun to grow recently [60]. Therefore, little is known about changes in romantic relationship quality during these different developmental stages. Moreover, despite studies that have shown that close friends are an essential component of romantic development [67, 68], understanding the mutual influences between friendships and romantic relationships continues to be an important challenge for developmental psychology. In fact, only a handful of empirical studies have examined similarities and differences in relationship quality with the most relevant members of individual social network, such as close friends and romantic partners [68, 69]. For this reason, it seems relevant to develop an equivalent measure for the study of friendships and romantic relationships during adolescence and early adulthood.

\section{Aims of the Study}

Given the aforementioned considerations, the purpose of this study was to develop an equivalent version of the FQS, the Romance Qualities Scale (RQS), which would be able to measure the qualitative aspects of romantic relationships. In particular, the aim of the present study was to: 1) evaluate 
the factor structure via confirmatory factor analysis; 2) test factorial invariance across independent sample extracts from different populations (middle-adolescents and early-adults); 3 ) investigate the reliability of the scale.

\section{METHOD}

\section{Participants and Procedure}

A total of 732 participants were recruited for the present study and divided into two age groups:

1) 381 middle-adolescents (182 males and 199 females) aged 16 to $19(M=17.83 ; S D=.84)$ who were attending three high schools in Florence (a Lyceum specializing in scientific studies, a Lyceum specializing in classical studies, a technical institute, and two vocational institutes).

2) 351 early-adults (161 males and 190 females) aged 20 to $23(M=21.62 ; S D=.76)$ who were studying at two departments of the university of Florence (the Psychology Faculty and the Law Faculty).

Similar to study 1, participants had Italian backgrounds and came from upper-middle socioeconomic classes. About $70 \%$ of their parents had a high school diploma or university degree (particularly, $44.3 \%$ of fathers had a high school diploma and $23.8 \%$ of them had a university degree; and $46.8 \%$ of mothers had a high school diploma and $21.7 \%$ of them had a university degree). Moreover, $95.2 \%$ of fathers were employed and only $4.8 \%$ of them were not employed; and $84.8 \%$ of mothers were employed and $15.2 \%$ of them were not employed.

The original version of the FQS was adapted for the relationship with romantic partners by replacing the word "friend" with that of "partner". Both equivalent versions are fully reported in the Appendix.

The RQS was administered in the classroom during school hours. Prior to commencing data collection, formal consent was obtained from parents and educational authorities for high school students. Participants were asked to respond to the questionnaire with reference to their current relationship. Subjects who were not engaged in a current romantic relationship were excluded from the analyses.

The final sample comprised 431 participants (179 males and 252 females) which was divided into two age groups: 205 middle-adolescents ( 87 males and 118 females) aged 16 to $19(M=17.68 ; S D=.87)$, and 226 early-adults $(92$ males and 134 females) aged 20 to $23(M=21.75 ; S D=.80)$.

\section{RESULTS}

\section{Preliminary Analyses}

First, we conducted preliminary analyses to test the normality of all the RQS items [35]. These analyses showed non-normal distribution of two items (items 6 and 21) in relation to the two groups considered, so we normalized these items through standard transformations (logarithmic). Following transformation, the values of asymmetry were within the range of +1 and $-1[36,37]$.

\section{Confirmatory Factor Analysis}

To test the factorial structure of the scale a confirmatory factor analysis was conducted on the sample of middle- adolescents [38] using the AMOS 5.0 statistical program [39].

Similar to the friendship version, multiple indices of fit were assessed to test for support of the model: the $\chi^{2}$ test, Comparative Fit Index (CFI; [43]), Tucker and Lewis Index (TLI; [44]), Root Mean Square Error Approximation (RMSE; [45]), and the Standardized Root Mean Square Residual (SRMR; [46]).

The model tested, like the FQS model, included 22 observed variables and five latent variables (see Fig. 1).

This model had satisfactory goodness-of-fit indexes, though chi square was again significant: $\chi^{2}=352.87, \mathrm{p}<$ $.001, \chi^{2} / \mathrm{df}=1.99, \mathrm{CFI}=.91, \mathrm{TLI}=.90, \mathrm{RMSEA}=.07$ (90\% CI: .06, .08), SRMS = .08.

Moreover, all 22 items of the scale saturated significantly on the five dimensions.

Finally, as for the FQS, the correlations among the five dimensions indicated a significant and positive relationship between the Companionship, Help, Security, and Closeness dimensions and a significant negative relationship between these factors and the Conflict dimension (Fig. 3).

\section{Factor Invariance}

After verifying the structural factor of the RQS, we proceeded to test the factorial invariance, using a multi-group model, across independent samples extracted from different populations [48] in order to examine the generalizability of the RQS. To this end, we used the middle-adolescent group, upon which a confirmatory factor analysis was conducted, as the calibration sample and the other group of subjects, the sample of early-adults, as the validation sample $[49,50]$.

To test invariance, as a preliminary step, we examined the fit of the RQS Baseline model. Following this, we tested the saturation invariance $(\lambda)$, factor covariance invariance $(\varphi)$ and, finally, error term invariance $(\delta)$.

The factor invariance results shown in Table $\mathbf{2}$ highlight the saturation, factor covariance, and error term invariance of the RQS.

\section{Internal Consistency}

The internal consistency coefficient (Cronbach alpha) for calibration and validation samples were respectively .74 and .75 for the Conflict dimension; .61 and .62 for the Companionship dimension; .82 and .84 for the Help dimension; .69 and .72 for the Security dimension; .74 and .78 for the Closeness dimension.

\section{DISCUSSION}

Similar to the FQS, the RQS also showed good psychometric properties, a satisfactory degree of generalizability, and internal consistency. Analysis confirmed that the RQS had the same multidimensional structure as the friendship version, highlighting satisfactory goodness-of-fit indices. Moreover, this structure was also found to be invariant with respect to the two age groups considered, confirming its generalizability between independent samples of different ages. 


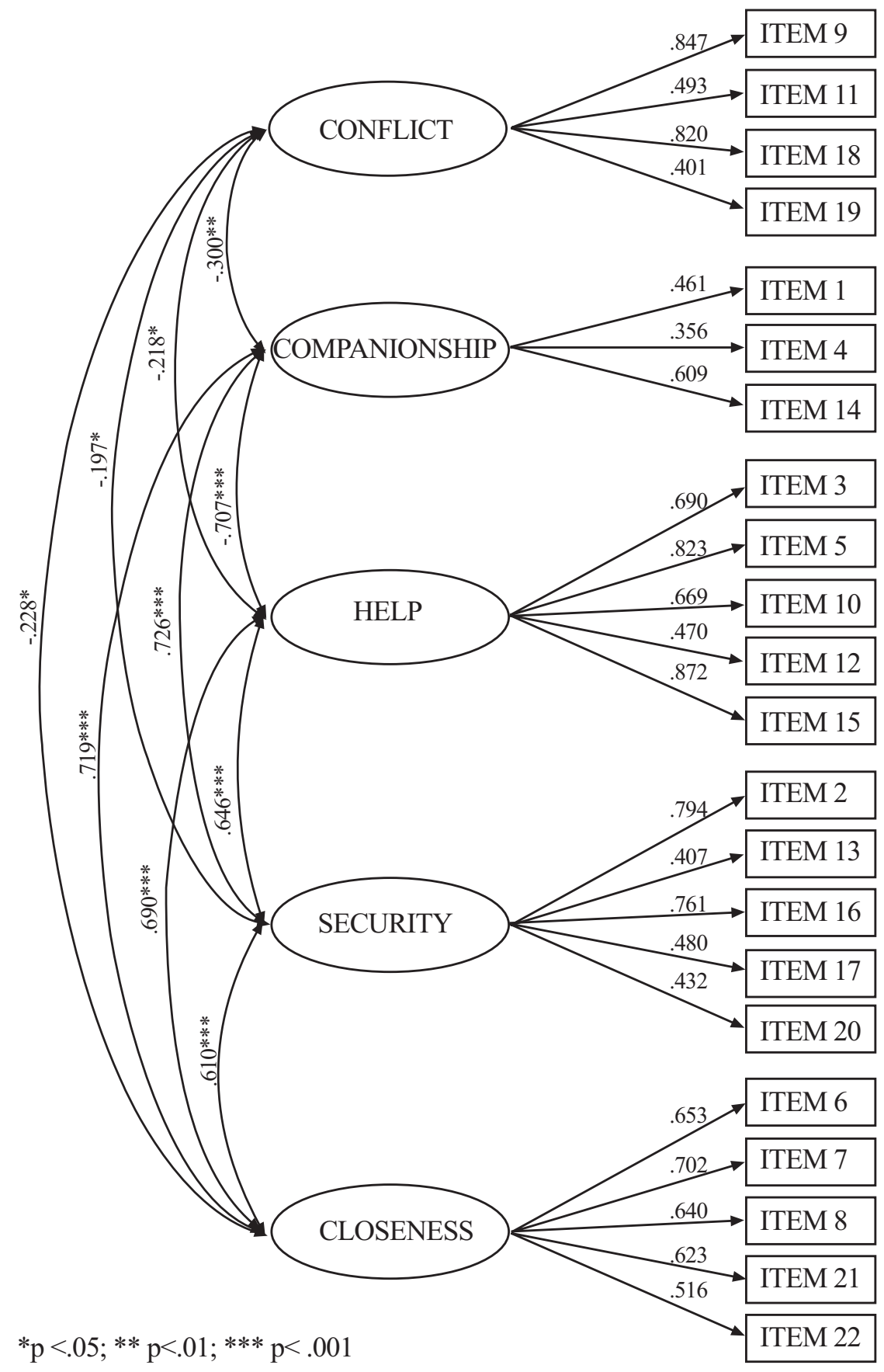

Fig. (3). Results of the confirmatory factor analysis conducted on the model of the RQS.

Finally, with regards to the reliability of the scale, all alpha values obtained allow the RQS to be considered a self-report scale with adequate internal consistency [52].

\section{CONCLUSION}

The aim of this research was to prepare a self-report instrument that would be capable of measuring different types of close relationships, like friendship and romantic relationships.

Overall, our studies have provided verification that the FQS and RQS are appropriate instruments to evaluate the perception that the individuals have of the quality of their close relationships. Even if the self-evaluative nature of these instruments does not guarantee the objective veridicity of the reports provided by the same respondents, overall the data that emerge from these scales constitute an information source that is particularly valuable in the field of studies on intimate relationships, in which many aspects remain inaccessible to observation or hetero-evaluation.

The FQS is a particularly reliable scale for measuring friendship, even in the Italian context and in relationships from early-adolescence to early-adulthood. The wide age range for which the FQS was adapted for the Italian population makes it an irreplaceable research instrument. The pos- 
Table 2. Index of the Factorial Invariance of the RQS: Saturation Invariance (Model 1), Factor Covariance Invariance (Model 2), and Error Term Invariance (Model 3)

\begin{tabular}{|c|c|c|c|c|c|c|c|}
\hline & $\chi^{2}$ & gdl & $\Delta \chi^{2}$ & $\Delta$ gdl & $\mathbf{p}\left(\Delta \chi^{2}\right)$ & CFI & RMSEA \\
\hline Baseline & 742.32 & 354 & - & - & - & .91 & $.0590 \%$ C.I.: .04; .05 \\
\hline Model 1 & 747.47 & 370 & 5.15 & 16 & $\mathrm{~ns}$ & .91 & $.0590 \%$ C.I.: .04; .05 \\
\hline Model 2 & 755.61 & 385 & 13.29 & 31 & ns & .91 & $.0590 \%$ C.I.: .04; .05 \\
\hline Model 3 & 793.44 & 408 & 51.12 & 54 & ns & .89 & $.0590 \%$ C.I.: .04; .05 \\
\hline
\end{tabular}

sibility of having a single instrument that is reliable over such a wide life span, from childhood to early adulthood, will allow longitudinal studies aimed at analyzing developmental diachronic changes in friendship quality of individuals belonging to very different age groups to be conducted.

Moreover, from a psychometric point of view, the RQS also was a good measure for assessing romantic relationships. However, from a conceptual point of view, we are aware that this scale does not investigate one of the fundamental aspects of romantic relationships, that being sexuality. Despite this, the adaption of this scale to couple relationships responds to the need to develop an instrument that uses a common conceptual framework for studying and comparing different types of close relationships.

In relation to this, perhaps the most interesting aspect of our results is the fact that the same structure was invariant in relation to the two different types of intimate relationship that we considered (friendship and romantic relationships). This result seems to therefore confirm the possibility of being able to use a single theoretical framework of reference for the study of different intimate relationships. Therefore, the present study enabled verification of the presence of the same general qualitative dimensions in best friend and partner relationships (genotypic similarity), dimensions that certainly are manifested differently in these different types of close relationships (phenotypic dissimilarity) [70].

Finally, these equivalent measures could enable the investigation of similarities and differences in friendships and romantic relationships within different developmental stages.

There are, however, some limitations to the present study. This study provides a detailed contribution to the verification of the construct validity of these equivalent measures in the Italian context. It would nevertheless be opportune to conduct further studies aimed at examining other types of validity. Despite its limitations, the results of the present study provide a useful starting point for the development of an instrument which can measure friendships and romantic relationships from early adolescence to early adulthood.

\section{Appendix. Italian Version of FQS/RQS}

\begin{tabular}{|c|c|c|c|c|c|c|c|c|}
\hline $\begin{array}{c}1 \\
\text { Assolutamente falso } \\
\text { [absolutely false] }\end{array}$ & $\begin{array}{c}2 \\
\text { Abbastanza falso } \\
\text { [quite false] }\end{array}$ & $\begin{array}{c}3 \\
\text { Né vero né falso } \\
\text { [neither true nor false] }\end{array}$ & $\begin{array}{c}4 \\
\text { Abbastanza vero } \\
\text { [quite true] }\end{array}$ & \multicolumn{5}{|c|}{$\begin{array}{c}5 \\
\text { Assolutamente vero } \\
\text { [absolutely true] }\end{array}$} \\
\hline \multicolumn{4}{|c|}{$\begin{array}{l}\text { 1. Io e il mio amico/partner passiamo tutto il nostro tempo libero insieme [My friend/partner and I spend all our free } \\
\text { time together] }\end{array}$} & 1 & 2 & 3 & 4 & 5 \\
\hline \multicolumn{4}{|c|}{$\begin{array}{l}\text { 2. Se ho qualche problema di studio, di lavoro o a casa posso parlarne con il mio amico/partner [If I have a problem at } \\
\text { school, at work, or at home, I can talk to my friend/partner about it] }\end{array}$} & 1 & 2 & 3 & 4 & 5 \\
\hline \multicolumn{4}{|c|}{$\begin{array}{l}\text { 3. Se altri mi dessero noia il mio amico/partner mi aiuterebbe [If other people were bothering me, my friend/partner } \\
\text { would help me] }\end{array}$} & 1 & 2 & 3 & 4 & 5 \\
\hline \multicolumn{4}{|c|}{ 4. Il mio amico/partner inventa delle cose divertenti da fare [My friend/partner thinks of fun things for us to do together] } & 1 & 2 & 3 & 4 & 5 \\
\hline \multicolumn{4}{|c|}{$\begin{array}{l}\text { 5. Il mio amico/partner mi aiuta quando sono in difficoltà [My friend/partner helps me when I am having trouble with } \\
\text { something] }\end{array}$} & 1 & 2 & 3 & 4 & 5 \\
\hline \multicolumn{4}{|c|}{$\begin{array}{l}\text { 6. Se il mio amico/partner dovesse trasferirsi in un'altra città penso che sentirei la sua mancanza [If my friend/partner } \\
\text { had to move away, I would miss him] }\end{array}$} & 1 & 2 & 3 & 4 & 5 \\
\hline \multicolumn{4}{|c|}{$\begin{array}{l}\text { 7. Quando faccio bene qualcosa il mio amico/partner è contento per me [When I do a good job at something, my } \\
\text { friend/partner is happy for me] }\end{array}$} & 1 & 2 & 3 & 4 & 5 \\
\hline \multicolumn{4}{|c|}{$\begin{array}{l}\text { 8. Qualche volta il mio amico/partner fa delle cose per me, che mi fanno sentire speciale [Sometimes my friend/partner } \\
\text { does things for me, or makes me feel special] }\end{array}$} & 1 & 2 & 3 & 4 & 5 \\
\hline
\end{tabular}


Appendix. Contd....

9. Qualche volta litigo anche molto violentemente con il mio amico/partner [Sometimes I quarrel even violently with my friend/ partner]

10. Se qualcuno mi desse noia penso che il mio amico/partner mi difenderebbe [My friend/partner would stick up for me if someone was causing me trouble]

11. Qualche volta il mio amico/partner mi tormenta e mi da noia anche se gli dico di non farlo [My friend/partner can bug me or annoy me even though I ask him not to]

12. Se avessi bisogno di soldi penso che il mio amico/partner me li darebbe [If I needed money my friend/partner would loan it to me]

13. Se dopo aver litigato anche violentemente con il mio amico/partner gli chiedessi scusa penso che egli continuerebbe ad essere arrabbiato con me [After having fought, even violently, with my friend/partner, if I said sorry to him or her, I think that he or she would continue to be angry with me]

14. Qualche volta io e il mio amico/partner stiamo insieme e parliamo dello studio, del lavoro e delle cose che ci piacciono [Sometimes my friend/partner and I just sit around and talk about things like study, work, and things we like]

15. Se avessi bisogno di qualcosa penso che il mio amico/partner mi aiuterebbe [My friend/partner would help me if I needed it]

16. Se c'è qualcosa che mi preoccupa e che non posso dire ad altri la dico al mio amico/partner [If there is something bothering me, I can tell my friend/partner about it even if it is something I cannot tell to other people]

17. Se io do fastidio al mio amico/partner e lui da noia a me dopo facciamo la pace facilmente [If my friend/partner or I do something that bothers the other one of us, we can make up easily]

18. Qualche volta io e il mio amico/partner litighiamo molto [My friend/partner and I can argue a lot]

19. Io e il mio amico/partner non andiamo d'accordo su molte cose [My friend/partner and I disagree about many things]

20. Se io e il mio amico/partner litighiamo anche violentemente ci chiediamo scusa e tutto torna a posto [If my friend/partner and I have a violent argument, we can say "I'm sorry" and everything will be alright]

21. Sono contento quando sono insieme al mio amico/partner [I feel happy when I am with my friend/partner]

22. Penso al mio amico/partner anche quando lui non c'è [I think about my friend/partner even when he or she is not around]

\begin{tabular}{|c|c|c|c|c|}
\hline 1 & 2 & 3 & 4 & 5 \\
\hline 1 & 2 & 3 & 4 & 5 \\
\hline 1 & 2 & 3 & 4 & 5 \\
\hline 1 & 2 & 3 & 4 & 5 \\
\hline 1 & 2 & 3 & 4 & 5 \\
\hline 1 & 2 & 3 & 4 & 5 \\
\hline 1 & 2 & 3 & 4 & 5 \\
\hline 1 & 2 & 3 & 4 & 5 \\
\hline 1 & 2 & 3 & 4 & 5 \\
\hline 1 & 2 & 3 & 4 & 5 \\
\hline 1 & 2 & 3 & 4 & 5 \\
\hline 1 & 2 & 3 & 4 & 5 \\
\hline 1 & 2 & 3 & 4 & 5 \\
\hline 1 & 2 & 3 & 4 & 5 \\
\hline
\end{tabular}

\section{ACKNOWLEDGEMENTS}

The research was supported by Monte dei Paschi di Siena Foundation in 2008 (ref. no 34935) -and 2009 (ref. no. 37877). The authors extend our tanks to all the subjects who participated.

\section{REFERENCES}

[1] Noller P, Feeney JA. Close relationships. Functions, forms and processes. New York: Psychology Press 2006.

[2] Bukowski WM, Hoza B, Boivin M. Measuring friendship quality during pre and early adolescence: The development and psychometric properties of the Friendship Qualities Scale. J Soc Pers Relat 1994; 11: 471-84.

[3] Hendrick SS. Understanding close relationships. Boston: Pearson Education, Inc 2004.

[4] Hendrick C, Hendrick SS. Close relationships. Thousand Oaks: Sage 2000.

[5] Laursen B, Bukowski WM. A developmental guide to the organisation of close relationships. Int J Behav Dev 1997; 21: 747-770.

[6] Noller P, Feeney JA, Peterson C. Personal relationships across the lifespan. New York: Psychology Press 2001.

[7] Brown BB. "You're going out with who?": Peer group influences on adolescent romantic relationships. In: Furman W, Brown BB, Feiring C, Eds. The development of romantic relationships in adolescence, New York: Cambridge University Press 1999; pp. 291329.
[8] Collins WA. More than myth: The developmental significance of romantic relationships during adolescence. J Res Adolesc 2003; 13: 1-24.

[9] Cohen S, Gottlieb BH, Underwood LG. Social relationships and health. In: Cohen S, Underwood LG, Gottlieb BH, Eds. Social support measurement and intervention: A guide for health and social scientists. Oxford: Oxford University Press 2000; pp. 3-25.

[10] Furman W, Shaffer L. The role of romantic relationships in adolescent development. In: Florsheim P, Eds. Adolescent romantic relations and sexual behavior: Theory, research, and practical implications. Lawrence Erlbaum Associates 2003; pp. 3-22.

[11] La Greca A, Harrison H. Adolescent peer relations, friendships, and romantic relationships: Do they predict social anxiety and depression? J Clin Child Adolesc Psychol 2005; 34: 49-61.

[12] Meier A, Allen G. Romantic relationships from adolescence to adulthood: Evidence from the national longitudinal study of adolescent health. Sociol Q 2009; 50: 308-335.

[13] Seiffge-Krenke I. Testing theories of romantic development from adolescence to young adulthood: Evidence of a developmental sequence. Int J Behav Dev 2003; 27: 519-531.

[14] Smetana JG, Campione-Barr N, Metzger A. Adolescent development in interpersonal and societal contexts. Annu Rev Psychol 2006; 57 : 255-286.

[15] Furman W. The measurement of friendship perceptions: Conceptual and methodological issues. In: Bukowski WM, Newcomb AF, Hartup WW, Eds. The company they keep. Cambridge: Cambridge University Press 1996; pp.41-65. 
[16] Furman W, Buhrmester D. Age and sex differences in perceptions of networks of personal relationships. Child Dev 1992; 63: 10315.

[17] Cunningham MR, Barbee AP. Social support. In: Hendrick C, Hendrick SS, Eds. Close relationships: A sourcebook. Thousand Oaks, CA: Sage 2000; pp. 273-85.

[18] Bukowski WM, Newcomb AF, Hartup WW. The company they keep: Friendship in childhood and adolescence. New York: Cambridge University Press 1996.

[19] Tani F. Le amicizie negli anni della scuola. Età Evolutiva 2000; 67: 52-59.

[20] Claes M. Friendship and personal adjustment during adolescence. J Adolesc 1992; 15: 39-55.

[21] Fonzi A, Tani F. Amici per la pelle: Le caratteristiche dei legami amicali nell'adolescenza. In: Caprara GV, Fonzi A, Eds. L'Età sospesa: Itinerari del viaggio adolescenziale. Firenze: Giunti 2000; pp. $90-120$.

[22] Berndt TJ. Exploring the effects of friendship quality on social development». In: Bukowski WM, Newcomb AF, Hartup WW, Eds. The company they keep: Friendship in childhood and adolescence. New York: Cambridge University Press 1996; pp. 346-65.

[23] Berndt TJ. Friendship quality and social development. Curr Dis Psychol Sci 2002; 11: 7-10.

[24] Hartup WW. Cooperation, close relationships, and cognitive development. In: Bukowski WM, Newcomb AF, Hartup WW, Eds. The company they keep: Friendship in childhood and adolescence. New York: Cambridge University Press 1996; pp. 213-37.

[25] Allen J, Porter M, Marsh P, McFarland F, McElhaney K. Two faces of adolescents' success with peers: Adolescents popularity, social adaptation and deviant behavior. Child Dev 2005; 76: 74760 .

[26] Rubin K, Chen X, Mcdougall P, Bowker A, Mckinnon J. The Waterloo Longitudinal Project: Predicting internalizing and externalizing problems in adolescence. Dev Psychopathol 1995; 7: 75164.

[27] Collins WA, Laursen B. Adolescent relationships: The art of fugue. In: Hendrick C, Hendrick S, Eds. Close relationships: A sourcebook. Thousand Oaks, CA: Sage 2000; pp. 59-69.

[28] Brown BB, Mory MS, Kinney D. Casting adolescent crowds in a relational perspective: Caricature, channel, and context. In: Montemayor R, Adams GR, Gullotta TP, Eds. Personal relationships during adolescence. USA: Sage 1994; pp. 123-167.

[29] Palmonari A, Pombeni ML, Kirchler E. Adolescents and their peer groups: A study on the significance of peers, social categorization processes and coping with developmental tasks. Soc Behav 1990; 5: 33-48.

[30] Tarrant M, Mackenzie L, Hewitt LA. Friendship group identification, multidimensional self-concept, and experience of developmental tasks in adolescence. J Adolesc 2006; 29: 627-640.

[31] Laursen B, Pursell G. Conflict in peer relationships. In: Rubin KH, Bukowski WM, Laursen B, Eds. Handbook of peer interactions, relationships, and groups. New York: Guilford Press 2009; pp. 267286.

[32] Shulman S, Laursen B. Adolescent perceptions of conflict in interdependent and disengaged friendships. J Res Adolesc 2002; 12: 353-372.

[33] Berndt TJ, Perry B. Benefits of friendship interview. Unpublished paper, University of Oklahoma. Norman, Oklahoma 1983.

[34] Fonzi A, Tani F, Schneider B. Adattamento e validazione su un campione italiano della scala sulla qualità dell'amicizia (F.Q.S.) di Bukowski, Hoza e Boivin. Giornale Italiano di Psicologia 1996; 23 : 107-22.

[35] Fox J. Applied regression analysis and generalized linear models. London: Sage Publications Inc 2008.

[36] Marcoulides GA, Hershberger SL. Multivariate Statistical Method: A First Course. Mahwah, NJ: Laurence Erlbaum Associates 1997.

[37] Muthén B, Kaplan D. A comparison of some methodologies for the factor analysis of non-normal Likert variables. Br J Math Stat Psychol 1985; 38: 171-89.

[38] Jöresborg KG, Sörbom D. LISREL 8: User's reference guide. Chicago: Scientific Software 1993.
[39] Arbuckle JL. Amos 6.0 user's guide. Spring House, PA: Amos Development Corporation 2005.

[40] Bollen K. Structural equations with latent variables. New York: Wiley 1989.

[41] Corbetta P. Metodi di analisi multivariata per le scienze sociali. Bologna: Il Mulino 1993.

[42] Primi C. Indici di bontà di adattamento nei modelli di equazioni strutturali. Firenze: Loggia dè Lanzi 2002.

[43] Bentler PM. Comparative fit indexes in structural models. Psychol Bull 1990; 107: 238-46.

[44] Tucker LR, Lewis C. A reliability coefficient for maximum likelihood factor analysis. Psychometrika 1973; 38: 1-10.

[45] Steiger JH, Lind JC. Statistically based tests for the number of common factors, Meeting of the Psychometric Society, Iowa City IA 1980.

[46] Bentler PM. EQS strucural equations program manual. Encino, CA: Multivariate Software 1995.

[47] Hu L, Bentler PM. Fit indices in covariance structure modelling: Sensitivity to underparameterized model misspecification. Psychol Methods 1998; 4: 424-453.

[48] Jöresborg KG. Simultaneous factor analysis in several populations. Psychometrika 1971; 36: 409-26.

[49] Bagozzi RP, Foxall GR.Construct validity and generalizability of the Kirton Adaption-Innovation Inventory. Eur J Pers 1995; 9: 18506.

[50] Reise SP, Widaman KF, Pugh RF. Confirmatory factor analysis and item response theory: Two approaches for exploring measurement invariance. Psychol Bull 1993; 114: 552-66.

[51] Meredith W. Measurement invariance, factor analysis, and factorial invariance. Psychometrika 1993; 58: 525-33.

[52] Nunnally JC, Bernstein IH. Psychometric Theory. New York: McGraw-Hill 1994.

[53] Feiring C. Concepts of romance in 15-year-old adolescents. J Res Adolesc 1996; 6: 181-200.

[54] Shulman S, Scharf M. Adolescent romantic behaviors and perceptions: Age- and gender- related differences, and links with family and peer relationships. J Res Adolesc 2000; 10: 99-118.

[55] Connolly J, Furman W, Konarski R. The roles of peers in the emergence of heterosexual romantic relationships in adolescence. Child Dev 2000; 17: 1395-1408.

[56] Lempers JD, Clark-Lempers DS. A functional comparison of samesex and opposite-sex friendship during adolescence. J Adolesc Res 1993; 8: 89-108.

[57] Richards MH, Crowe P, Larson R, Swarr A. Developmental patterns and gender differences in the experience of peer companionship during adolescence. Child Dev 1998; 69: 154-163.

[58] Neemann J, Hubbard J, Masten AS. The changing importance of romantic relationship involvement to competence from late childhood to late adolescence. Dev Psychopathol 1995; 7: 727750 .

[59] Neemann J, Hubbard J, Masten AS. The changing importance of romantic relationship involvement to competence from late childhood to late adolescence. Dev Psychopathol 1995; 7: 727-750.

[60] Furman W, Brown BB, Feiring C. The devolopment of romantic relationships in adolescence. Cambridge: Cambridge University Press 1999.

[61] Furman W, Flanagan A. The influence of earlier relationships on marriage: An attachment perspective. In: Halford WK, Markman HJ, Eds. Clinical handbook of marriage and couples interventions. USA: Wiley 1997; pp. 179-202.

[62] Beyers W, Seiffge-Krenke I. Are friends and romantic partner "the best medicine"? How the quality of other close relations mediates the impact of changing family relationships on adjustment. Int $\mathbf{J}$ Behav Dev 2007; 31: 559-568.

[63] Levesque RGR. The romantic experience of adolescents in satisfying love relationships. J Youth Adolesc 1993; 22: 219-251.

[64] Furman W, Buhrmester D. Children's perceptions of the personal relationships in their social networks. Dev Psychol 1985; 21: 10161024.

[65] Brown BB. You're going out with who?: peer group influences on adolescent romantic relationships. In: Furman W, Brown BB, Feiring C, Eds. The Development of Romantic Relationships 
in Adolescence. Cambridge: Cambridge University Press 1999; pp. 291-329.

[66] Connolly J, Craig W, Goldberg A, Pepler D. Mixed-gender groups, dating, and romantic relationships in early-adolescence. J Res Adolesc 2004; 14: 185-207.

[67] Connolly J, Sroufe LA. Capacity for intimate relationships. A developmental construction. In: Furman W, Brown BB, Feiring C, Eds. The development of romantic relationships in adolescence. cambridge: Cambridge University Press 1999; pp. 125-147.

[68] Connolly J, Goldberg A. Romantic relationships in adolescence. The role of friends and peers in their emergence and development.
In: Furman W, Brown BB, Feiring C, Eds. The Development of Romantic Relationships in Adolescence. Cambridge: Cambridge University Press 1999; pp. 266-290.

[69] Tani F, Fonzi A. Relazioni di amicizia e relazioni sentimentali nel passaggio dall'adolescenza all'età adulta. Età Evolutiva 2005; 80: 90-98.

[70] Adler TF, Furman W. A model for children's relationships and relationship dysfunctions. In: Duck S, Ed., Handbook of personal relationships: Theory research and interventions. USA: Wiley 1988; pp. 211-232.

(C) Ponti et al.; Licensee Bentham Open.

This is an open access article licensed under the terms of the Creative Commons Attribution Non-Commercial License (http://creativecommons.org/licenses/ by-nc/3.0/) which permits unrestricted, non-commercial use, distribution and reproduction in any medium, provided the work is properly cited. 